DOI: $10.15593 / 2224-9826 / 2015.4 .11$

УДК 625.712 .34

\title{
О.В. Моисеева, В.И. Клевеко
}

Пермский национальный исследовательский политехнический университет, Пермь, Россия

\section{АНАЛИЗ АВАРИЙНЫХ СЛУЧАЕВ С УЧАСТИЕМ ПЕШЕХОДОВ В Г. ПЕРМИ}

\begin{abstract}
В связи с ростом городов, увеличением количества автомобилей на душу населения и численности населения количество аварийных случаев, участниками которых становятся пешеходы, непрерывно растет.

По статистическим данным Госавтоинспекции за 2014 и 2015 г. по г. Перми были составлены наглядные диаграммы, которые отражают число погибших, пострадавших и общее количество ДТП в городе. Анализ полученных диаграмм показал, что количество ДТП с пешеходами за указанный период значительно возросло. Выявлены пересечения улиц г. Перми, которые являются наиболее опасными для пешеходных участников дорожного движения.

Из неутешительных статистических данных становится очевидным, что сложившаяся ситуация на дорогах требует незамедлительного решения.

Рациональным решением данной проблемы является строительство надземных и подземных пешеходных переходов. Строительство таких переходов может быть затруднительно изза загруженности города, сложности устройства объездных путей на время строительства, значительных затрат и вложений. Но эксплуатация таких пешеходных переходов более безопасна как для пешеходов, так и для водителей автомобилей.

Новым видом транспортных развязок является организация пешеходного перехода в разных уровнях с организацией движения пешеходов на уровне земли. Такая конструкция перехода является простой и удобной в эксплуатации, пешеходы избавляются от вынужденных подъемов и спусков на значительную высоту (глубину). Переходы такого вида еще не используются в России, но нашли широкое применение за рубежом, например в г. Эдинбурге, Великобритания.

Ключевые слова: авария, пешеход, пешеходный переход, безопасность дорожного движения, надземный пешеходный переход, подземный пешеходный переход.
\end{abstract}

\section{O.V. Moiseeva,V.I. Kleveko}

Perm National Research Polytechnic University, Perm, Russian Federation

\section{ANALYSIS OF ACCIDENT CASES INVOLVING PEDESTRIANS IN PERM}

In connection with the growth of cities, increasing the number of vehicles per capita and population growth, the number of accidents to which pedestrians are continuously growing.

According to the statistics of the traffic police in 2014 and 2015 the city of Perm were drawn visual diagrams, which reflect the number of deaths, the number of victims and the total number of 
traffic accidents in the city. Analysis of the graphs showed that the number of accidents with pedestrians during this period has increased significantly. Identified the intersection of the city of Perm, who are the most dangerous for pedestrian traffic participants.

Because of disappointing statistics becomes apparent that the current situation on the roads requires an immediate solution.

A rational solution to this problem is the construction of overground and underground pedestrian crossings. Construction of these transitions can be difficult due to the congestion of the city, the complexity of the device detours during construction, significant costs and investments. But the use of such pedestrian crossings safer for pedestrians and motorists themselves.

Most new type of transport interchanges is the organization of a pedestrian crossing on different levels with the organization of pedestrian traffic at ground level. This design transition is simple and convenient in operation, pedestrians get rid of forced ascents and descents to a considerable height (depth). Transitions of this type has not yet used in Russia, but widely used overseas, for example in Edinburgh, UK.

Keywords: accident, pedestrian, pedestrian crossing, traffic safety, elevated pedestrian crossings, underpass.

Развитие городов, увеличение уровня автомобилизации и рост численности населения влекут за собой увеличение числа как пешеходов, так и водителей автомобилей.

По статистическим данным, каждый год в России случается около 200 тыс. аварий, в которых погибает примерно 25 тыс. человек, получают травмы 250 тыс. человек.

Самыми уязвимым и незащищенными участниками дорожного движения являются пешеходы. По данным Госавтоинспекции, количество аварий с участием пешеходов в России за 2014 год насчитывает 11811 случаев [1-3].

Аварийные ситуации на дорогах с участием пешеходов случаются как по вине самих пешеходов, так и по вине водителей автомобилей. В любом случае это зачастую приводит к смертельным исходам.

Можно выделить следующие основные причины возникновения аварийных ситуаций на ПП:

- невнимательность водителей;

- невнимательность пешеходов;

- недостаточная зона видимости;

- сложная дорожная ситуация.

Места, в которых чаще всего происходят ДТП с пешеходом, могут быть самыми разнообразными:

- нерегулируемый пешеходный переход (ПП);

- регулируемый ПП;

- места, не предназначенные для ПП.

По состоянию на 2014 г. Пермь входит в пятерку городов с наибольшим числом аварий при участии пешеходов в России [4]. 
Показатели не самые утешительные. В течение 10 месяцев в Перми произошло 548 аварий с пешими участниками дорожного движения, в результате которых погибло 75 человек, 507 человек получили травмы.

Наземный пешеход типа «зебра» является самым простым и дешевым видом ПП, но при этом значительно увеличивает вероятность возникновения аварий [5-6].

Статистику аварий, произошедших на пешеходных переходах в г. Перми в 2014 г., можно представить диаграммой, которая приведена на рис. 1.

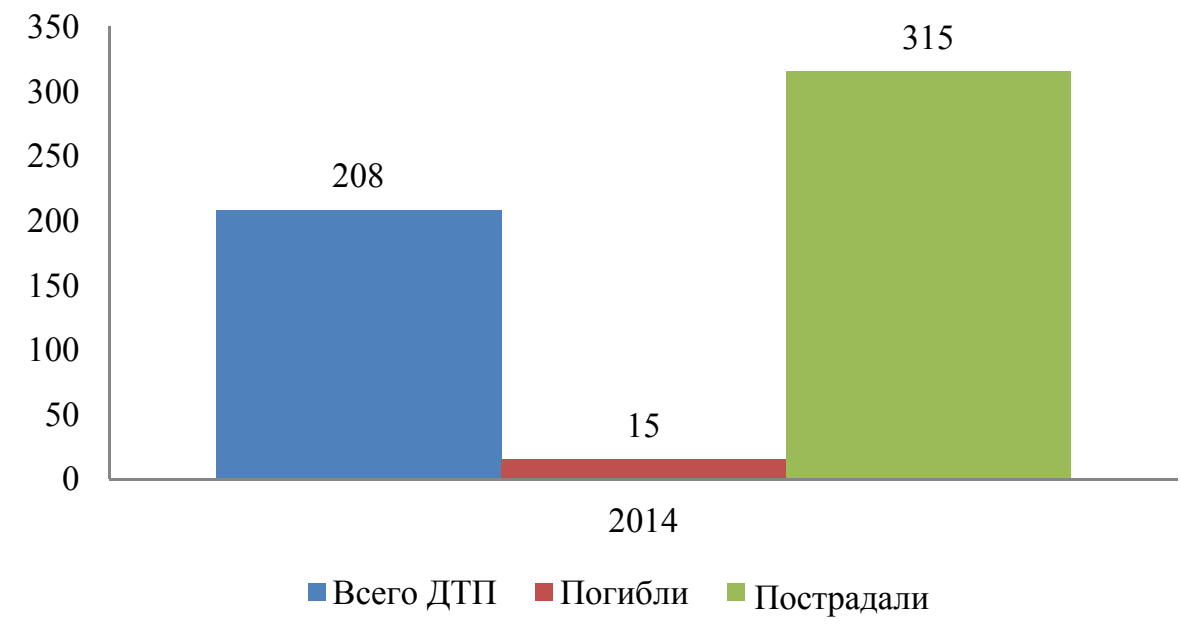

Рис. 1. ДТП на пешеходных переходах г. Перми (2014 г.)

Из диаграммы видно, что 7 \% аварий на ПП в 2014 г. закончились смертельным исходом.

По данным Госавтоинспекции на 04.09.2015 г., за период с января по август 2015 г. зарегистрировано 273 аварии, 132 из которых произошли на регулируемых ПП и 141 - на не регулируемых. Диаграммы по этим данным представлены на рис. 2-4. Из сравнения общих данных по количеству аварийных ситуаций за 2014-2015 гг. видно, что общее количество аварий на ПП значительно выросло. По диаграммам, отражающим количество аварий на регулируемых и не регулируемых пешеходных переходах, можно увидеть, что, несмотря на то что переход оборудован всеми необходимыми элементами, количество ДТП не сильно отличается от переходов, которые не имеют соответствующих элементов. 


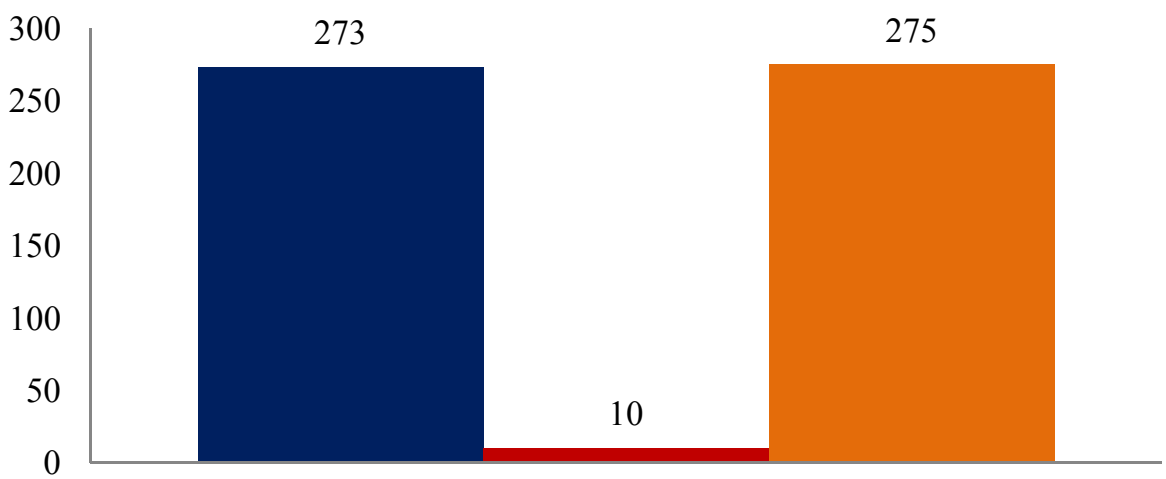

2015

- Всего ДТП $\quad$ Погибли $\quad$ Пострадали

Рис. 2. ДТП на пешеходных переходах г. Перми (2015 г.)

140

132

120

100

80

60

40

31

20

0
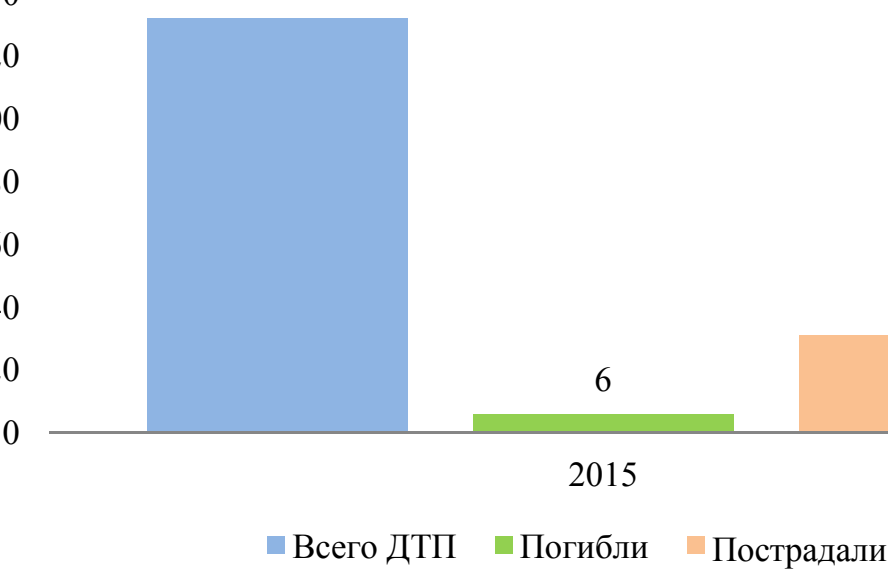

Рис. 3. ДТП на регулируемых пешеходных переходах г. Перми (2015 г.)

Наличие на перекрестке светофора не делает пешеходный переход достаточно безопасным. Необходимы дополнительные меры, обеспечивающие безопасность всем участникам движения.

Таким образом, по данным Пермской Госавтоинспекции, самыми аварийными улицами г. Перми являются $[7,8]$ :

- перекресток ш. Космонавтов и ул. Стахановской;

- ул. Соликамский тракт, 1;

- перекресток ш. Космонавтов и ул. Плеханова;

- перекресток ул. Куйбышева и ул. Коминтерна; 
- ул. Уинская, 9;

- перекресток ул. Маршала Рыбалко и ул. Оборонщиков;

- перекресток ул. Локомотивной и ул. Энгельса;

- район остановки «Давыдова», ул. Мира, 120.

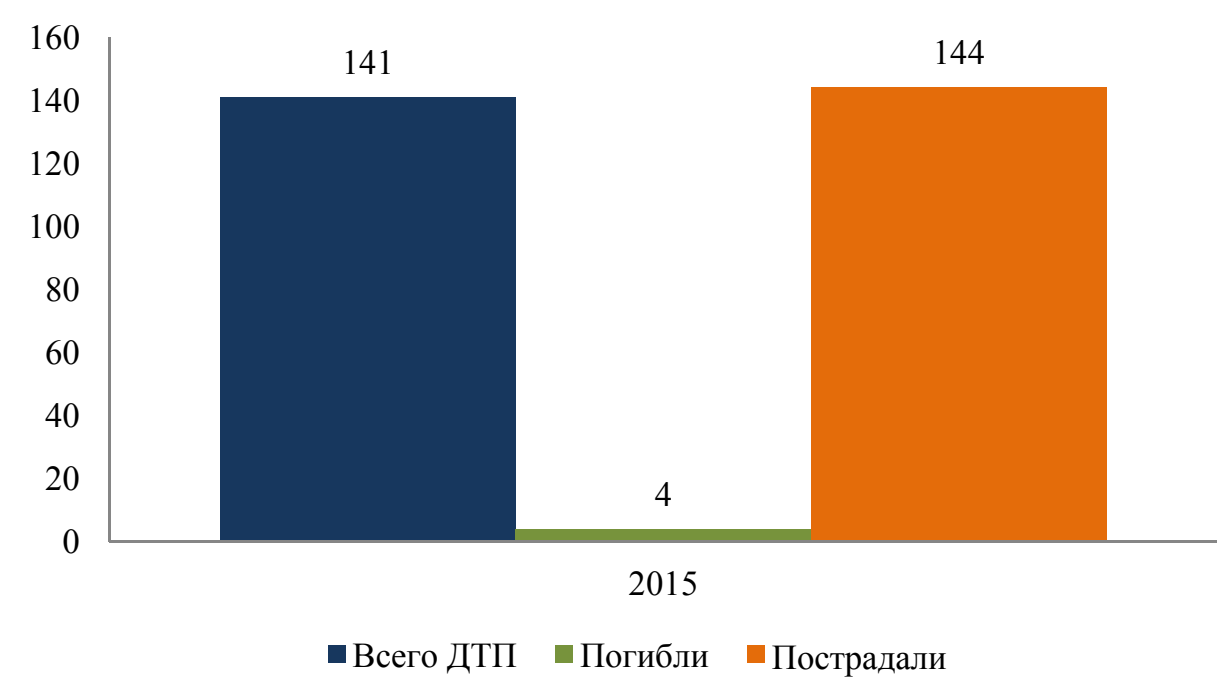

Рис. 4. ДТП на не регулируемых пешеходных переходах г. Перми (2015 г.)

Уменьшения количества аварий с участием пешеходов можно добиться различными способами. К ним относятся установка защитных ограждений, сопровождение сигнала светофора звуковым эффектом, установка камер на перекрестках. Но самым эффективным является устройство безопасных пешеходных переходов, в которых не может существовать контакт автомобиль - пешеход. Такими переходами являются надземный и подземный.

Надземный пешеходный переход представляет собой конструкцию в виде пешеходного моста, располагающегося над полотном проезжей части. Возведение такой конструкции не влияет на функционирование действующей транспортной системы, чем очень привлекательно. Стоимость строительства надземного пешеходного перехода составляет порядка 30 млн руб.

Подземный пешеходный переход представляет собой пешеходный тоннель, проходящий под проезжей частью. Возведение такого вида пешеходного перехода может быть очень затруднительно в силу загруженности городской транспортной сети. Стоимость возведения 
подземного пешеходного перехода значительно больше и составляет порядка 100 млн руб. [9, 10].

Единственным недостатком этих видов пешеходных переходов является неудобство их использования для самих пешеходов (подъем на значительную высоту, спуск на значительную глубину).

Еще одним решением проблемы может послужить конструкция перехода с разными уровнями [11]. Общий вид данных переходов приведен на рис. 5, 6. При такой конструкции движения пешеходов организуется в уровне земли, автомобили двигаются на другом уровне.

За рубежом такая конструкция переходов получила широкое распространение. Она очень удобна своей конфигурацией, но имеет большую трудоемкость. Успешный опыт использования таких конструкций уже существует. Наглядный пример пешеходного перехода в разных уровнях можно понаблюдать в г. Эдинбурге, Великобритания. Сама конструкция перехода очень проста. Организацию движения пешеходов осуществляют на уровне земли, что облегчает эксплуатацию переходов самим пешеходам [12].

Подводя итоги, можно сказать, что не регулируемый ПП и переход вида «зебра» уже давно не справляются со своим прямым назначением. Внедрение альтернативных видов ПП в транспортную сеть городов России может значительно уменьшить количество аварийных ситуаций на дорогах с участием пешеходов [13-15].

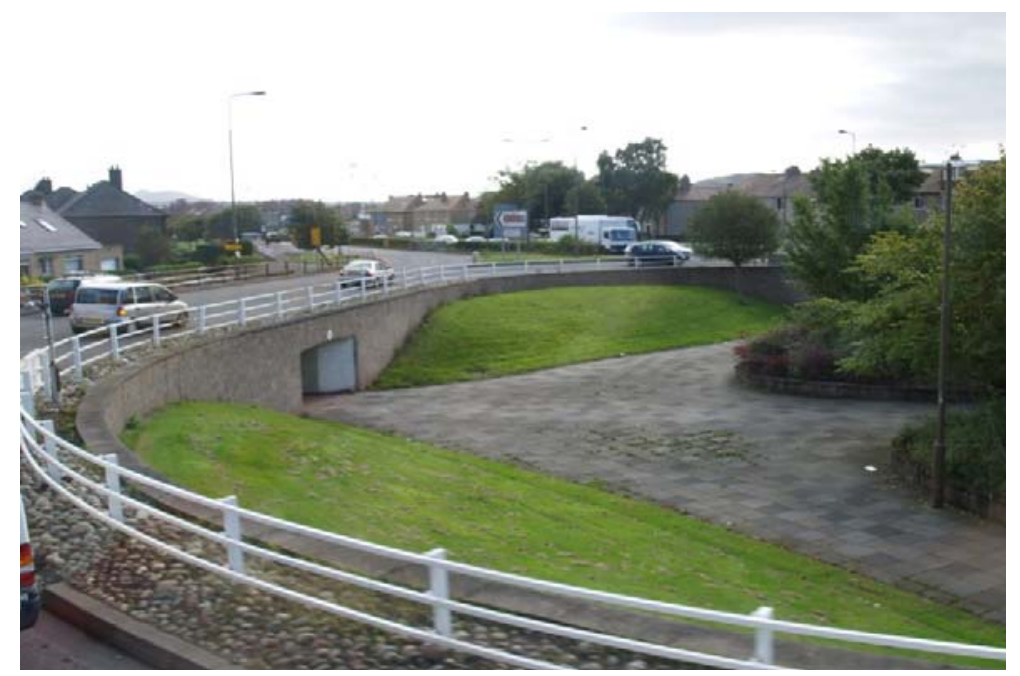

Рис. 5. Конструкция пешеходного перехода в разных уровнях с организацией движения пешеходов на уровне земли 


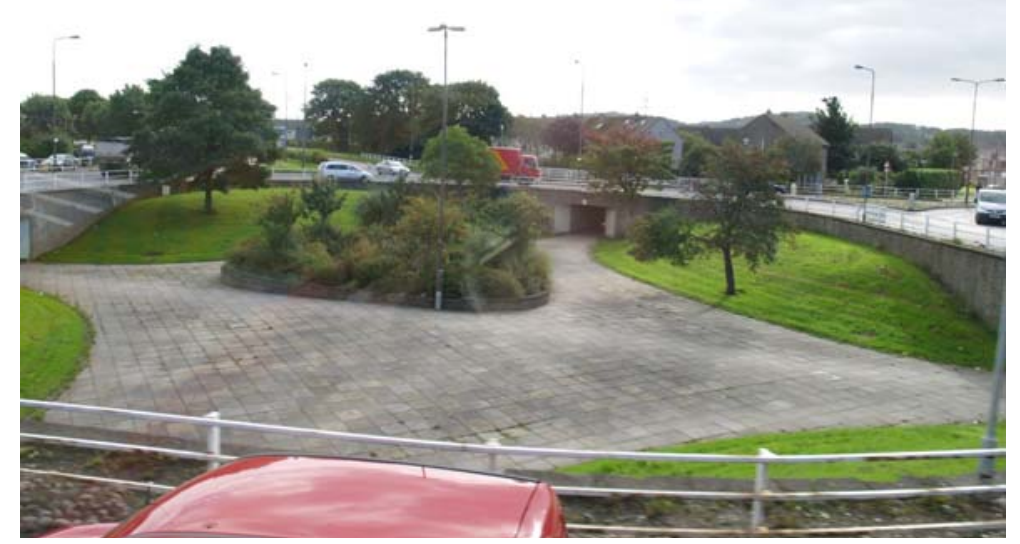

Рис. 6. Общий вид организации транспортной развязки в разных уровнях (г. Эдинбург, Великобритания)

Строительство новых видов переходов значительно дороже «зебры», но при этом можно отметить массу преимуществ:

- уменьшение аварийных случаев;

- экономия времени пешеходов и водителей;

- придание городу нового архитектурного облика;

- увеличение проходимости транспортной сети города.

\section{Библиографический список}

1. Официальный сайт Управления ГИБДД по Пермскому краю. URL: http://gibdd.perm.ru/index.php?do= cat\&category=dtp.

2. Коноплянко В.И. Организация и безопасность дорожного движения. - М.: Транспорт, 1991. - 183 с.

3. Официальный сайт компании SFpark. - URL: http://sfpark.org.

4. Официальный сайт T7-информ. - URL: http: //t7-inform.ru/s/ audionews/ 20141209122226.

5. Якимов М.Р. Транспортные системы крупных городов: моногр. - Пермь: Изд-во Перм. гос. техн. ун-та, 2008. - 184 с.

6. Третьякова П.А., Клевеко В.И. Современные методы повышения эффективности транспортных систем городов // Вестник Пермского национального исследовательского политехнического университета. Строительство и архитектура. - 2012. - С. 101-108. 
7. Генеральный план города Перми . - URL: http://www.permgenplan.ru.

8. Мастер-план города Перми. - URL:. http://www.permgenplan.ru/ content/view/9/13.

9. Третьякова П.А., Клевеко В.И. Современные подходы к проектированию транспортных систем городских территорий // Модернизация и научные исследования в транспортном комплексе: материалы междунар. науч.-техн. конф. - 2012. - Т. 2. - С. 155-161.

10. Кашапова К.Р., Клевеко В.И., Моисеева О.В. Экономическое обоснование технологии устройства котлована для сооружения подземного пешеходного перехода // Вестник Пермского национального исследовательского политехнического университета. Прикладная экология. Урбанистика. - 2014. - № 4 (16). - С. 59-70.

11. Половникова А.Э., Клевеко В.И. Выбор рационального типа пешеходных переходов с учетом безопасности движения пешеходов // Модернизация и научные исследования в транспортном комплексе: материалы междунар. науч.-техн. конф. - 2012. - Т. 2. - С. 356-361.

12. Wang R., Ruskin H.J. Modeling traffic flow at a single-lane urban roundabout // Computer Physics Communications. - 2002. - Vol. 147, no. 1-2. - P. 570-576.

13. Официальный сайт сетевого издания «Центр дорожной информации». - URL: http://road.perm.ru/index.php?id=1370.

14. Телегин В.Г., Клевеко В.И. Проблемы транспортной системы города Перми и пути их решения // Сборник научных трудов SWorld. 2014. - T. 1, № 1. - С. 11-17.

15. Телегин В.Г., Бурдина С.Г., Клевеко В.И. Анализ возможности повышения безопасности дорожного движения на существующей развязке «Сосновый бор» в городе Перми // Вестник Пермского национального исследовательского политехнического университета. Строительство и архитектура. - 2015. - № 1. - С. 120-134. DOI: 10.15593/2224-9826/2015.1.09

\section{References}

1. Ofitsial'nyi sait Upravleniia GIBDD po Permskomu kraiu [Official website of Management of Traffic police on the Perm Region], available at: http://gibdd.perm.ru/index.php?do= cat\&category=dtp.

2. Konoplianko V.I. Organizatsiia i bezopasnost dorozhnogo dvizheniia [Organization and traffic safety]. Moscow: Transport, 1991. 183 p. 
3. Ofitsial'nyi sait kompanii SFpark [Official website of company SFpark], available at: http://sfpark.org.

4. Ofitsial'nyi sait T7-inform [Official website T7-inform], available at: http://t7-inform.ru/s/ audionews/20141209122226

5. Iakimov M.R. Transportnye sistemy krupnyikh gorodov [The transportation system of large cities]. Perm: Permskii gosudarstvennyi tehnicheskii universitet, 2008. $184 \mathrm{p}$.

6. Tret'iakova P.A., Kleveko V.I. Sovremennye metody povysheniia effektivnosti transportnykh sistem gorodov [Modern methods of increase efficiency of transport systems of cities]. Vestnik Permskogo natsional'nogo issledovatel'skogo politekhnicheskogo universiteta. Stroitel'stvo $i$ arkhitektura, 2012, pp. 101-108.

7. General'nyi plan goroda Permi [The General plan of Perm], available at: http://www.permgenplan.ru.

8. Master-plan goroda Permi [The master plan of Perm], available at: http://www.permgenplan.ru/content/view/9/13.

9. Tret'iakova P.A., Kleveko V.I. Sovremennye podkhody k proektirovaniiu transportnykh sistem gorodskikh territorii [Modern approaches to the design of transport systems of urban territories]. Materialy Mezhdunarodnoi nauchno-teknicheskoi konferentsii "Modernizatsiia i nauchnye issledovaniia v transportnom komplekse”, 2012, vol. 2, pp. 155-161.

10. Kashapova K.R., Kleveko V.I., Moiseeva O.V. Ekonomicheskoe obosnovanie tekhnologii ustroistva kotlovana dlia sooruzheniia podzemnogo peshekhodnogo perekhoda [Economic justification of technology excavation for the construction of pedestrian underpasses]. Vestnik Permskogo natsional'nogo issledovatel'skogo politekhnicheskogo universiteta. Prikladnaia ekologiia. Urbanistika, 2014, no. 4 (16), pp. 59-70.

11. Polovnikova A.E., Kleveko V.I. Vybor ratsionalnogo tipa peshekhodnykh perekhodov s uchetom bezopasnosti dvizheniia peshekhodov [The choice of rational type of pedestrian crossings with safety of movement of pedestrians]. Materialy Mezhdunarodnoi nauchnoteknicheskoi konferentsii "Modernizatsiia $i$ nauchnye issledovaniia $v$ transportnom komplekse”, 2012, vol. 2, pp. 356-361.

12. Wang R., Ruskin H.J. Modeling traffic flow at a single-lane urban roundabout. Computer Physics Communications, 2002, vol. 147, no. 1-2, pp. 570-576. 
13. Ofitsial'nyi sait setevogo izdaniia "Tsentr dorozhnoy informatsii" [Official websaite online edition of the "Road information centre"], available at: http://road.perm.ru/index.php?id=1370.

14. Telegin V.G., Kleveko V.I. Problemy transportnoi sistemy goroda Permi i puti ikh resheniia [The problems of the transport system of Perm and the ways of their solution]. Sbornik nauchnykh trudov SWorld, 2014, vol. 1, no. 1. pp. 11-17.

15. Telegin V.G., Burdina S.G., Kleveko V.I. Analiz vomozhnosti povysheniia bezopasnosti dorozhnogo dvizheniia na sushchestvuiuschei razviazke "Sosnovyi bor" v gorode Permi [The analysis of the possibility of improving of road safety at the roundabout "Sosnovyi Bor" of Perm city]. Vestnik Permskogo natsional'nogo issledovatel'skogo politekhnicheskogo universiteta. Stroitelstvo i arkhitektura, 2015, no 1, pp. 120-134. DOI: 10.15593/2224-9826/2015.1.09

Получено 30.09.2015

\section{Об авторах}

Моисеева Олеся Васильевна (Пермь, Россия) - студентка Пермского национального исследовательского политехнического университета (614990, г. Пермь, Комсомольский пр., 29, e-mail: lesja.moiseeva@mail.ru).

Клевеко Владимир Иванович (Пермь, Россия) - кандидат технических наук, доцент кафедры «Строительное производство и геотехника» Пермского национального исследовательского политехнического университета (614990, г. Пермь, Комсомольский пр., 29, e-mail: vlivkl@mail.ru).

\section{About the authors}

Olesia V. Moiseeva (Perm, Russian Federation) - Student, Perm National Research Polytechnic University (29, Komsomolsky av., Perm, 614990, Russian Federation, e-mail: lesja.moiseeva@mail.ru).

Vladimir I. Kleveko (Perm, Russian Federation) - Ph.D. in Technical Sciences, Associate Professor, Department of Building Production and Geotechnics, Perm National Research Polytechnic University (29, Komsomolsky av., Perm, 614990, Russian Federation, e-mail: vlivk1@mail.ru). 